\title{
Research on the Construction of the Virtual Simulation Experimental Teaching Center of Economics and Management Majors
}

\author{
Hang $\mathrm{Gao}^{1}$ \\ ${ }^{1}$ Business School Shandong, University of Political Science and Law, Jinan, China
}

\begin{abstract}
Practical teaching is one of the core links in the teaching activities of economics and management majors, and it is also an important part of cultivating students to use energy and comprehensive quality. Virtual simulation experiment is an indispensable content in the cultivation of economicsa and management majors, and has become the main direction of the experimental teaching reform of these majors. This paper probes into the necessity of the establishment of virtual simulation experimental teaching center. This paper proposes suggestions on improving the operation of the virtual simulation experimental center of economics and management majors, and provides references for the practical teaching and talent cultivation of other majors.
\end{abstract}

\section{INTRODUCTION}

With the development of computer, communication, virtual reality and other technologies, virtual simulation experimental teaching has emerged. Virtual simulation experimental teaching can not only break through the limitation of time and space, but also complete the teaching function which is difficult to be completed in real experiment. The virtual simulation experiment teaching has also been paid much attention by relevant government departments. The outline of the national medium - and long-term plan for education reform and development (2010-2020) explicitly proposes the establishment of virtual laboratories. The long-term development plan of educational informatization (20112020) proposes to select and develop 500 application platforms and 1,500 sets of virtual simulation experiment systems. In 2013, the ministry of education issued the notice on the construction of national virtual simulation experiment teaching center, and decided to select the national virtual simulation experiment teaching center. In 2013, Ministry of Education issued a notice on the construction of a national-level virtual simulation experimental teaching center, which decided to select national-level centers. The notice requires that the candidate centers must be national or provincial experimental teaching demonstration centers. Therefore, the virtual simulation experimental teaching centers were established on the basis of the experimental teaching demonstration centers

The virtual simulation experimental teaching center is the product of the integration of information technology and experimental teaching. How to construct the virtual simulation experimental teaching center well under the new technical condition still has the problems of construction ideas and methods. Therefore, it is of great value to put forward the construction scheme that conforms to the characteristics of the economics and management majors to promote the operation of virtual simulation experimental teaching centers.

\section{STATUS QUO OF ViRTUAL SimULATION EXPERIMENTAL TEACHING AT HOME AND ABROAD}

The first history of virtual simulation technology can be traced back to the 1960s. The early simulation technology takes the computer as the carrier of the simulation model and has the functions of visualization, rapidity and simplification. The technology has the advantage of greatly reducing the human, material and financial costs of real experiments, and is welcomed by business executives, developers and users. In recent decades, virtual simulation technology keeps pace with the times and has made great progress. The technology has also made great progress in adapting to environmental characteristics and improving human-computer interaction. This technology differentiates the simulation technology which combines distributed simulation and interactive simulation. In order to realize distributed interactive simulation technology, network technology, supporting environment technology, organization and management are all important key supports. Among them, network technology is the foundation of distributed interactive simulation, supporting environment technology is the core, and organization and management is the control signal. From the overall perspective of

gaohang@sdupsl.edu.cn 
theory and practice, virtual simulation technology can indeed help experimenters to improve their thinking ability and innovation consciousness, and cultivate talents who can meet the requirements of senior positions.

The research and application of virtual simulation experiment teaching in foreign countries are relatively early. As early as the 1990s, the United States applied virtual simulation technology in teaching and included virtual laboratory in its strategic planning of scientific research and development. The United States established a laboratory committee in 1991 to invest in virtual laboratories in various academic fields to promote the teaching of virtual simulation experiments.At present, in the research and application of virtual simulation experiment teaching of economics and management majors, foreign universities have also carried out some explorations. First, they have accelerated the application of augmented reality, stereoscopic display and other new technologies that have great influence on the teaching of virtual simulation experiment in education. Second, they have added mobile interactive experiments based on handheld devices and remote collaborative experiments based on telepresence technology to their online courses. Third, they have increased investment and actively explored appropriate business models to enhance the construction of virtual simulation experiment resources. Fourth, they have built a future teaching laboratory with a complete virtual experimental environment.

\section{The Necessity of Virtual Simulation EXPERIMENTAL TEACHING IN ECONOMICS AND MANAGEMENT MAJORS}

\subsection{Virtual Simulation Technology Has Advantages in Talent Cultivation in Universities}

With the change of economic structure, the economic management activities of modern enterprises become more complex and comprehensive. The need for highly skilled people is more urgent. The cultivation process of high-skilled talents must highlight the cultivation of students' practical ability. Virtual simulation experimental teaching is to use virtual simulation technology to build a business simulation environment, let students play a certain role in the simulation environment to complete work tasks, so as to improve the practical ability of students. This mode of teaching can make up for the shortage of theoretical teaching, and can build a complex and diverse business environment with low cost to improve students' ability to apply comprehensive knowledge. In this way, students' comprehensive ability and quality can be improved, and the goal of cultivating applied, compound and innovative talents in economics and management can be realized.

\subsection{Carrying Out Virtual Simulation Experimental Teaching is the Requirement of the Development Trend of Higher Education}

Economics and management majors focus on the cultivation of students' practical ability and vocational ability. Internship in an enterprise is one of the effective ways to improve the comprehensive skills of college students majoring in this field. However, due to the risks and confidentiality of management positions, it is common for interns to have no access to management work and experience the complexity and variability of enterprise operation. As an innovative practical teaching mode, virtual simulation experimental teaching can arouse students' learning enthusiasm. This teaching mode can also promote the transformation of students from knowledge to ability, effectively improve their practical ability, and improve the quality of personnel training for economics and management majors[1].

\subsection{Virtual Simulation Experimental Teaching can Effectively Improve the Employability of University Students}

The employment positions of graduates majoring in economics and management is mainly in accounting, logistics, marketing, business administration and other fields. These positions work closely with each other, and their business and operation processes have strong intersection, collaboration, relevance and interaction. According to a survey of employers, these positions have higher requirements on graduates' professional ability and quality. These requirements include executive ability, problem solving ability, communication and collaboration ability, negotiation ability, professionalism, team spirit, etc. By building a virtual business environment, students can train in an environment that is basically the same as a real enterprise, so as to effectively train their professional ability and quality. In the course of practice, students can understand the interrelationship between enterprises, various departments and positions of enterprises, and master the multi-professional knowledge and skills across departments and positions through observation, communication or job rotation.

In the business environment of virtual simulation and comprehensive practical training, college students majoring in economics and management need to complete the task of establishing enterprises. They have to operate new businesses in a competitive environment and use innovative methods to solve operational problems. During the training, college students participated in product innovation, management and operation, brand design, creativity and other competitions, which improved their ability of innovation and entrepreneurship. 


\section{The Construction TARget of the VIRTUAL SIMULATION EXPERIMENTAL TEACHING CENTER OF ECONOMICS AND MANAGEMENT MAJORS}

One of the taegets of the construction of the virtual simulation experimental teaching center of economics and management majors is to simulate the environment and business process of enterprise operation. The virtual social economic management activities can provide college students with the environment and conditions to simulate the experiment. College students use relevant network technology and multimedia technology to form a virtual comprehensive market. This enables college students to fully understand the operation process of various types of enterprises and the main businesses they carry out, and master practical skills in a certain field.

Another major target of the construction of the virtual simulation experimental teaching center of economics and management majors is to simulate the roles of each postions. According to the position setting of real enterprises, the center sets corresponding positions in a virtual way and makes corresponding decisions according to the changes in the environment, so as to cultivate students' ability to use comprehensive knowledge and cooperate and communicate. This can train college students to make sound business decisions in the virtual environment[2].

In addition, the third target of the construction of the virtual simulation experiment teaching center for economics and management majors is to cultivate the knowledge, ability and quality of college students. This needs to be carried out in terms of teaching quality, teaching schedule, experimental effect, data processing, comprehensive analysis, logical judgment, problem solving, innovation and entrepreneurship (as shown in figure 1).

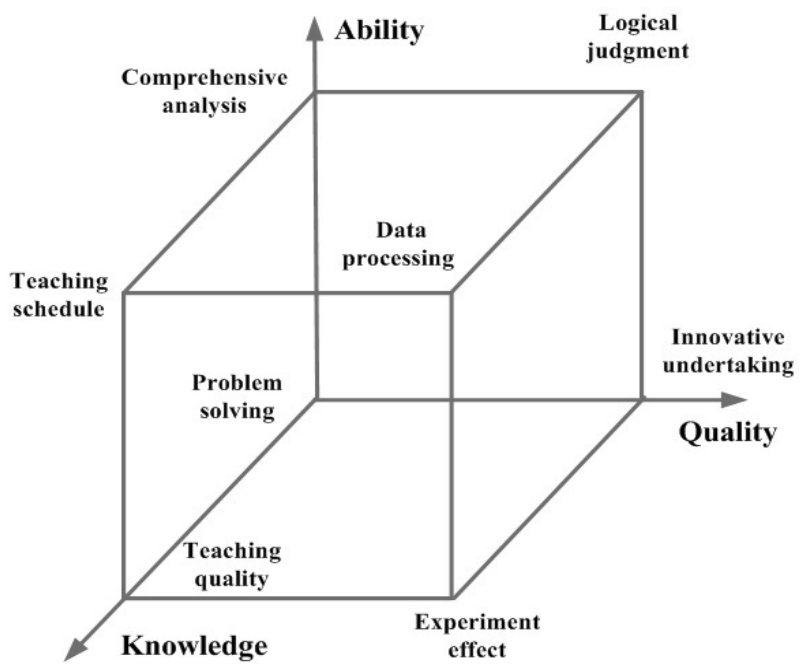

Figure 1. The three-dimensional talent training mode supported by virtual simulation experiment

\section{Suggestions ON StREngthening the CONSTRUCTION OF THE VIRTUAL SIMULATION EXPERIMENTAL TEACHING CENTER OF ECONOMICS AND MANAGEMENT MAJORS}

\subsection{Carrying Forward the Supporting Role of Smart Campus}

Virtual simulation platform needs good network environment support. Virtual simulation laboratory is a system that takes computer network as the core and connects virtual instruments through the network to realize data acquisition, analysis and remote operation. Relying on the construction of smart campus, the university makes extensive use of cloud computing, big data, virtualization and other technologies to connect virtual equipment through the network to build a data processing system. With the rapid development of global information technology, a good campus network environment is not limited to wired network coverage of the campus. Campus network must achieve wireless network coverage on the basis of wired coverage[3]. Only good campus network foundation support, can meet the needs of virtual simulation platform construction. In this way, it is convenient for students, teachers and other researchers to conduct experiments and research at any time and any place, and to make full use of the laboratory equipment.

\subsection{Comprehensively Promoting the Construction of Teaching Resources of Virtual Simulation}

The integration of rich, applicable and innovative virtual simulation experiment teaching resources is the key to realize virtual simulation experimental teaching and ensure good experimental teaching effect. Combined with the professional advantages of economics and management, the center should develop the virtual experiment teaching with the thought of subject orientation and group navigation. In the construction of experimental teaching resources, universities can follow the logic of environmental research, enterprise behavior simulation, comprehensive experiment of crossdisciplinary virtual simulation (see figure 2). Universities can explore the virtual simulation teaching resources of " open project resource library - $\mathrm{O} 2 \mathrm{O}$ experimental course group". With the help of database, case database, teaching software and other auxiliary resources for experimental teaching, universities can build a core resource library of open experimental projects, including experimental projects of economy, management and entrepreneurship[4]. At the same time, universities should build a group of virtual simulation course resources that are used both online and offline to serve the characteristics of economic management majors. 


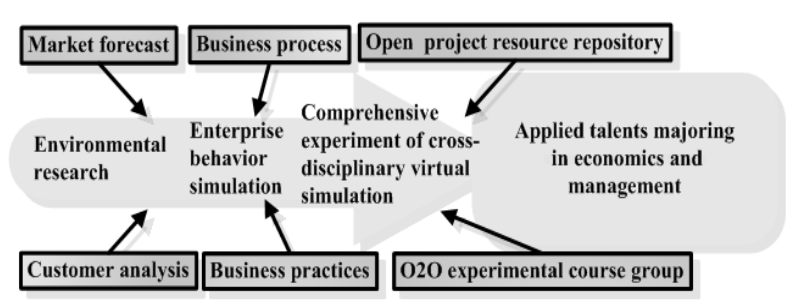

Figure 2. The frame work system of experimental resourses

\subsection{Strengthening the Teaching Staff Construction of the Virtual Simulation Experimental Teaching Center}

The vrtual simulation experimental teaching center should set up experimental teaching team based on the experimental curriculum. The team needs to select teachers with high academic level and rich experience in experimental teaching to be the person in charge, and offer comprehensive and innovative virtual simulation experiment courses mainly through the virtual simulation experimental teaching platform. In addition, the team should participate in further study and training to master the latest trends of experimental teaching. The center should encourage experimental teachers to combine "teaching, learning and research", incubate excellent scientific achievements into the content of virtual simulation experiment, optimize the content of experimental teaching, and improve the quality of virtual simulation experiment teaching. In addition, the center should encourage professional teachers to translate excellent scientific research achievements into actual experimental teaching content, especially into innovative experimental content[5].

\subsection{Constructing a Multi-dimensional Virtual Simulation Experimental Teaching System}

The center should adhere to the ability-oriented talent training program and creatively construct a multidimensional virtual simulation experimental teaching system for economics and management majors. The system should take the direction of "promoting the reform of experimental teaching methods such as autonomous learning, inquiry learning, collaborative learning and entrepreneurial learning under the information condition".On the basis of adapting to the needs of economic and social development, the system should aim at "cultivating students' core abilities such as analytical ability, creativity and leadership".

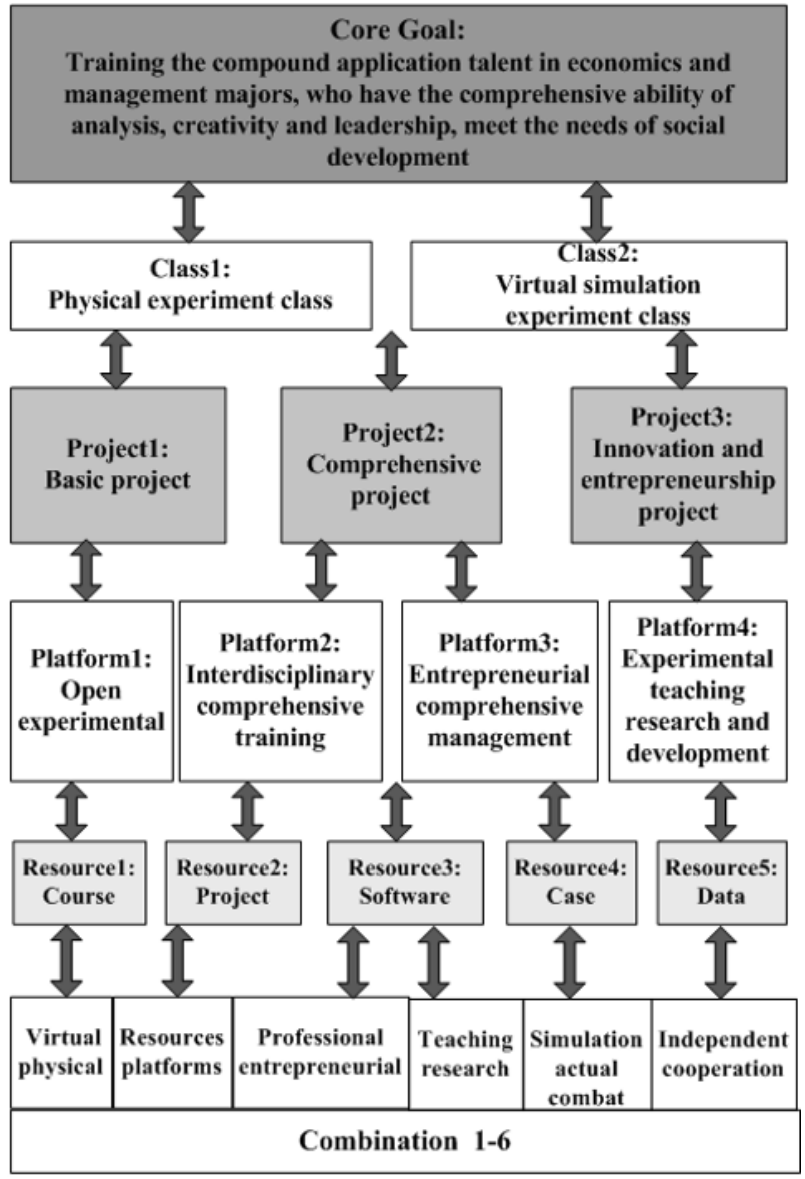

Figure 3. The "123456" virtual simulation experiment teaching system

First, the system should establish a core goal, that is the center should train the compound application talent in economics and management majors, who have the comprehensive ability of analysis, creativity and leadership, meet the needs of social development. Second, the center should create two classes, namely the physical experiment class and the virtual simulation experiment class. Third, the center should carry out three types of experimental teaching projects, including basic, comprehensive, innovation and entrepreneurship. Fourth, the center should build four experimental platforms, including open experimental platform, interdisciplinary comprehensive training platform, entrepreneurial comprehensive management platform and experimental teaching research and development platform. Fifth, the center should integrate five types of resources, including courses, projects, software, cases, data and other resources[6]. Sixth, the center should coordinate in six aspects, including the combination of virtual resources and physical resources, resources and platforms, professional resources and entrepreneurial resources, experimental teaching and scientific research, simulation and actual combat, and independent research and development and cooperation (see figure 3 ). 


\section{CONCLUSION}

With the rapid development of computer technology and network, virtual simulation has become one of the important means of practical teaching of economics and management majors. Virtual simulation experiment teaching is an important way to improve the quality of education and cultivate innovative talents in China. The virtual simulation experiment teaching center is the main body of virtual simulation experiment teaching. The construction effect of the center has a profound influence on the teaching quality of virtual simulation experiment. The reform of virtual simulation experiment teaching is an important direction of the present teaching reform of economics and management majors. This is also the inevitable requirement of cultivating compound application talents. This paper discusses the construction of the virtual simulation experimental teaching center in the hope of providing reference for the reform of the real experimental teaching of economics and management majors. This paper expounds the necessity of the construction of virtual simulation experimental teaching center for economics and management specialty, and then puts forward some suggestions on the construction of the center.

\section{ACKNOWLEDGMENT}

Fund: This study was funded by youth academic innovation team of management science and engineering of SDUPSL. This study was supported by the general teaching research project of SDUPSL ( Research on the construction of "golden courses" in virtual simulation experiment teaching of economics and management majors under the background of national first-class undergraduate courses ).

\section{REFERENCES}

1. Y. C, "Zhang. Research on the construction of university economic management laboratory under the characteristics of the new era,"Rural economy and technology,vol.34,pp.289-290,April 2019.

2. Y. Cai, "On the cultivation of experimental basic ability of college students,"Experimental technology and management, vol.32,pp.18-21, October 2015.

3. L. Jiang, "Construction of practical teaching quality monitoring system for economics and management majors in application-oriented universities ,'Jiangsu science and technology information,vol.36,pp.5759, March 2019.

4. Y. L. Liu, Y. Q, "Wu. Research on the construction of cross-specialty business simulation operation and training platform for economic management with ERP as the core," Journal of jiangxi university of science and technology, vol.35,pp.77-81,April 2014.

5. S. Bao, "Exploration and practice of the connotation of "entrepreneurship and innovation" talents training in economics and management specialty from the perspective of virtual simulation teaching," Intelligence, vol.26,pp.183-186,October 2019.

6. H. L. Wang, X. W, “ Geng. Reform and practice of practical teaching model in universities based on "entrepreneurship and innovation" training ,"Journal of higher education,vol.97,pp.53-55,January 2019. 